\title{
FLORA DE GRÃO-MOGOL, MINAS GERAIS: SAPINDACEAE
}

\author{
MARÍA SILVIA FERRUCCI
}

Instituto de Botánica del Nordeste, Casilla de Correo 209, 3400 Corrientes, Argentina.

FerrucCI, M.S. 1991. Sapindaceae. In R. Spichiger (ed.) Flora del Paraguay 16: 1-144, fig. 1-51.

Ferrucci, M.S. 1995. Sapindaceae. In B.L. Stannard (ed.) Flora of Pico das Almas: Chapada Diamantina, Bahia, Brazil. Royal Botanical Gardens. Kew, p. 581-585.

FERruCCI, M.S. 1998. Sapindaceae. In A.T. Hunziker (ed.) Flora fanerogámica Argentina 52: 1-44.

Radlkofer, L. 1892-1900. Sapindaceae. In C.F.P. Martius, A.W. Eichler \& I. Urban (eds.) Flora brasiliensis. Frid. Fleischer. Leipzig, vol. 13, pars 3, p. 225-658, tab. 58-123.

Radlkofer, L. 1931-1934. Sapindaceae. In H.G.A. Engler (ed.) Das Pflanzenreich. Wilhelm. Engelmann. Berlin, 165 (Heft 98a-h), p. 1-1539, fig. 1-46.

1. Plantas trepadoras leñosas con zarcillos. Hojas bicompuestas. Estípulas presentes.

2. Fruto esquizocárpico, mericarpos samaroideos con la porción seminífera en el ápice. Cáliz dialisépalo 3. Tallo con cámbium único.

4. Tallo recto. Folíolos 0,9-2,1 cm x 0,5-1,2 cm. Fruto de contorno suborbicular, sin constricción debajo del lóculo.

4'. Tallo geniculado. Folíolos 3-8,5 cm x 1,5-5 cm. Fruto de contorno ovado, con constricción debajo del lóculo................................................................................................. reticulata

3'. Tallo con más de un cámbium.

5. Tallo con 5 cámbiumes radiales. Porción seminífera del mericarpo con cresta dorsal notable.

5'. Tallo con un cámbium central y 3-10 cámbiumes periféricos.

6. Tallo con 8-10 cámbiumes periféricos. Fruto glabro . S. paradoxa 6'. Tallo con 3-4(5) cámbiumes periféricos. Fruto con la porción seminífera pubescente o vellosa. 7. Tallo subterete. Folíolos enteros o dentados. Porción seminífera sin cresta dorsal........................... S. lethalis

7'. Tallo hexangular, con 3 costillas agudas y prominentes. Folíolos con 2-4(5) dientes subapicales, raro enteros. Porción seminífera con cresta dorsal angosta.

$2^{\prime}$. Fruto capsular subcarnoso, rojo. Cáliz con 2 de los sépalos internos soldados en su mayor parte.

1'. Árboles, a veces arbustos o sufrútices. Estípulas ausentes.

8. Hojas bicompuestas. Pétalos pequeños en relación a los sépalos, sin escama basal o con 1 ó 2 pliegues en la base de la lámina. Cápsula loculicida, semilla con arilo carnoso.

8'. Hojas compuestas.

9. Fruto con 3 mericarpos samaroideos, con la porción seminífera en el ápice. 9'. Fruto capsular.

10. Pétalos sin escama basal. Disco nectarífero completo, desigual. Cápsula pluriseminada. Semillas aladas S. purpurascens S. acutidentata 10'. Pétalos con escama basal. Disco nectarífero completo, 5-lobado. Cápsula 1-3 seminada. Semillas ariladas.

11. Cáliz dialisépalo. Folíolos coriáceos, dentado-serrados Paullinia carpopodea

11'. Cáliz gamosépalo. Folíolos cartáceos, enteros Cupania paniculata

12. Lámina con 6-18 folíolos, éstos de 1,6-4,8 cm x 0,8-2,4 cm, envés con domacios foveolados o urceolados . M. marginata

12'. Lámina con 4-12 folíolos, éstos de 3,3-12,7 x 1,8-5,2 cm, envés con domacios en bolsillo o urceolados, o sin domacios.

13. Venas laterales de primer orden rectas, ascendentes..... M. juglandifolia 13'. Venas laterales de primer orden curvas, ascendentes M. guianensis

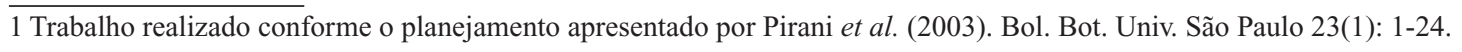




\section{Cupania L.}

Árboles o arbustos monoicos. Hojas compuestas, paripinnadas, sin estípulas. Tirsos dobles, raro simples, axilares o subterminales. Flores actinomorfas, blanquecinas o de color crema. Cáliz 5-mero, dialisépalo. Corola 5-mera, pétalos con escama basal bipartida, vellosa. Disco nectarífero completo. Androceo con 8 estambres. Gineceo 3-carpelar, 1 óvulo por carpelo. Cápsulas loculicidas. Semillas ariladas.

1.1. Cupania paniculata A.St.-Hil., A.Juss. \& Cambess. in A.St.-Hil., Fl. Bras. merid. 1: 388, tab.80. 1828.

Arbustos 0,5-3(-4) m alt. Indumento denso, amarillento a castaño, en tallos jóvenes, ejes de la hoja e inflorescencia. Lámina con 6-12 folíolos, subsésiles, coriáceos, dentado-serrados, revolutos, oblongos, haz lustroso, envés opaco, pubescente, 3-15,5 cm long., 2-6 cm lat. Inflorescencias parciales subsésiles. Flores 4-6 mm long., de color crema. Pétalos largamente unguiculados. Disco glabro. Filamentos estaminales vellosos. Gineceo velloso. Frutos coriáceos, turbinados, 3-lobados, estípite breve, 1,2-1,7 cm long., 1,2-1,5 cm lat.; epicarpo ocráceo pubescente, endocarpo velloso. (Fig. 3. E)

Assis et al. CFCR 11352 (CTES, SPF); Giulietti et al. CFCR 9843 (CTES, SPF); Pirani et al. CFCR 8545 (SPF), CFCR 12832 (CTES, SPF); Silva et al. CFCR 13258 (CTES, SPF); Zappi et al. CFCR 13109 (CTES, SPF).

Bahia y Minas Gerais, en “cerrados”. En Grão-Mogol, en suelo arenoso fino con afloramientos rocosos; especie heliófila frecuente en el "cerrado". Florece en junio-julio; fructifica en noviembre.

\section{Dilodendron Radlk.}

Árboles dioicos; hojas bicompuestas, paripinnadas, raro ejes secundarios imparipinnados, estípulas ausentes. Inflorescencias fasciculadas, tirsos dobles, axilares o subterminales. Flores actinomorfas, amarillentas. Cáliz 5-mero. Corola 3-5-mera, a veces ausente; pétalos reducidos, a veces con 1-2 pliegues en la base de la lámina. Disco nectarífero. Androceo con 8 estambres. Gineceo 3-carpelar, l óvulo por carpelo. Cápsulas loculicidas. Semillas con arilo carnoso.

2.1. Dilodendron bipinnatum Radlk., Sitzungsber. Math.Phys. Cl. Königl. Bayer. Akad. Wiss. München 8: 355. 1878.

Árboles 5-20 m alt. Indumento de pelos ocráceos a blanquecinos en ejes de la hoja e inflorescencia. Lámina con (2-)6-10 folíolos, raquis secundario con 10-16 foliólulos; foliólulos sésiles o subsésiles, ovado-lanceolados a ovados, dentado-serrados, haz pubérulo, envés pubérulo a pubescente, 1,8-6,7 cm long., 1,3-2,1 cm lat. Flores 5-6,5 mm long. Pétalos 1,4-1,6 mm long. Disco glabro. Filamentos estaminales gla- bros. Gineceo glabriúsculo o pubérulo. Frutos leñosos, trígono-ovoideos u -obovoideos, 2,7-3,3 mm long., 2-2,7 cm lat., epicarpo glabro, endocarpo pubérulo. (Fig. 2. C-D)

\section{Pirani et al. CFCR 880 (CTES, SPF)}

Brasil, Bolivia, Perú y N de Paraguay, en selvas ribereñas o isletas de selva. En Grão-Mogol, en "mata ciliar". Florece en junio-setiembre y fructifica en agosto-octubre. Nombres vernáculos: "saboneteira", "mulher-pobre".

\section{Magonia A.St.-Hil.}

Árboles monoicos. Hojas compuestas, paripinnadas, deciduas, estípulas ausentes. Inflorescencias en ramas desnudas, tirsos simples, raro dobles, axilares o terminales. Flores zigomorfas. Cáliz 5-mero. Corola 5-mera, pétalos oblanceolado- u oblongoangostos, purpúreos en la haz, verdosos en el envés. Disco nectarífero completo, en parte simple y en parte doble. Androceo con 8(7-9) estambres. Gineceo 3-carpelar, 6-8 óvulos por carpelo. Cápsulas loculicidas. Semillas aladas.

3.1. Magonia pubescens A.St.-Hil., Bull. Sci. Soc. Philom. Paris 78. 1824.

(= M. glabrata A. St. -Hil., Bull. Sci. Soc. Philom. Paris 78. 1824.)

Árboles 5-20 m alt., glabros o pubescentes. Indumento blanquecino en ejes de la hoja; ejes de la inflorescencia y verticilos florales con pelos de color azufre-verdoso; pelos glandulares en inflorescencia y cáliz. Lámina 6-10 folíolos, sésiles o subsésiles, subcoriáceos, oblongos, obovado- u ovado-angostos, enteros, haz glabro o pubérulo, envés glabriús- culo o pubescente; 7-12,4 mm long., 2-4,2 cm lat. Cincinos largamente pedunculados. Pétalos 0,9-1,7 cm long. Filamentos estaminales glabros. Frutos leñosos, trígono-globosos o subesféricos, 8,5-12 cm x 6,4-11,5 cm diám. (Fig. 2. H-I)

Pirani et al. CFCR 13551 (CTES, SPF).

Norte, este y centro-oeste de Brasil, E de Bolivia y N de Paraguay, en "cerrados". En Grão-Mogol, en "cerradão". Florece en junio-setiembre y fructifica en octubre-diciembre del próximo año. 
4. Matayba Aubl.

Árboles o arbustos monoicos. Hojas compuestas, paripinnadas, sin estípulas. Tirsos dobles, raro simples, axilares o subterminales. Flores actinomorfas, blanquecinas o de color crema. Cáliz 5-mero, gamosépalo. Corola 5-mera, pétalos con escama basal bipartida, vellosa. Disco nectarífero completo. Androceo con 8 estambres. Gineceo 3-carpelar, 1 óvulo por carpelo. Cápsulas loculicidas. Semillas ariladas.

4.1. Matayba guianensis Aubl., Hist. pl. Guiane 1: 331; tab. 128 (excluido el fruto). 1775.

Arbustos o árboles hasta $10 \mathrm{~m}$ alt. Indumento de pelos breves amarillentos, en ejes de la hoja e inflorescencia. Lámina con (2)4-12 folíolos, con peciólulo, cartáceos, enteros, revolutos, discolores, oblongos, elípticos, ovados u obovado-angostos, ápice obtuso o retuso, envés glabro a pubérulo, domacios ausentes o presentes, 1 o varios, en bolsillo o urceolados, 3,3-10,8 cm long., 1,8-4,3 cm lat., venas laterales de primer orden curvas, ascendentes. Flores 3,2-4,5 mm long., blanquecinas. Pétalos brevemente unguiculados. Disco glabro. Filamentos estaminales pilosos. Gineceo pubescente. Frutos coriáceos, rojizos, trígono-globosos, brevemente estipitados, 0,95-1,5 cm long., 0,8-1,8 cm lat.; epicarpo verrucoso, pubérulo, endocarpo velloso. (Fig. 3. D)

Assis et al. CFCR 11513 (CTES, SPF); Freire-Fierros et al. CFCR 12628; Furlan et al. CFCR 708 (CTES, SPF); Harley et al. 25002 (CTES, K, SPF); Pirani et al. CFCR 12631 (CTES, SPF); Silva et al. CFCR 12661 (CTES, SPF).

En Suriname, Guayana Francesa, Tobago, Perú y Brasil (desde Amazonas hasta Santa Catarina). En Grão-Mogol, es un arbusto que vive en "cerrado perturbado". Florece en noviembre y fructifica en enero.

4.2. Matayba juglandifolia (A.St.-Hil., A.Juss. \& Cambess.) Radlk., Sitzungsber. Math.- Phys. Königl. Bayer. Akad. Wiss. München 9: 535. 1879.

Arbustos o árboles hasta $12 \mathrm{~m}$ alt. Indumento de pelos blanquecinos o amarillentos adpresos en tallo joven y ejes de la inflorescencia. Lámina con 4-8 folíolos, con peciólulo breve, cartáceos, enteros, revolutos, oblongos, oblongo-anchos u obovado-angostos, ápice retuso o redondeado, haz lustroso, envés opaco, glabriúsculo, a veces domacios en bol- sillos, 4,3-12,7 cm long., 2,6-5,2 cm lat.; venas laterales de primer orden curvas, ascendentes. Flores 4-5,75 mm long., blanquecinas. Pétalos brevemente unguiculados. Disco glabro. Filamentos estaminales pubescentes. Frutos coriáceos, trígono-globosos, brevemente estipitados, ca. 1,1 cm long., ca. $1,35 \mathrm{~cm}$ lat.; epicarpo verrucoso, glabriúsculo, endocarpo con pelos ferrugíneos. (Fig. 3. C)

\section{Pirani et al.CFCR 8487 (SPF).}

Paraná, Rio de Janeiro, São Paulo y Minas Gerais. En Grão-Mogol, en interior de "mata de encosta". Florece en setiembre hasta diciembre, fructifica en noviembre-diciembre.

4.3. Matayba marginata Radlk., Sitzungsber. Math.-Phys. Cl. Königl. Bayer. Akad. Wiss. München 9: 634. 1879.

Arbustos o árboles hasta $6 \mathrm{~m}$ alt. Hojas en los ápices de las ramas. Indumento de pelos amarillentos en tallos jóvenes, ejes de las hojas e inflorescencias. Lámina con 6-18 folíolos, con peciólulo breve, cartáceos, enteros, revolutos, discolores, oblongos o el ápice emarginado, redondeado, obtuso o retuso, envés pubérulo, pluri-foveolado, o - urceolado, 1,64,8 cm long., 0,8-2,4 cm lat. Flores 3,5-4 mm long., color crema. Pétalos brevemente unguiculados. Disco glabro. Filamentos estaminales pubescentes. Gineceo piloso. Frutos coriáceos, rojizos, trígono-globosos, brevemente estipitados, 1-1,2 cm long., 1,1-1,4 cm lat.; epicarpo glabriúsculo, endocarpo blanco a ferrugíneo velloso. (Fig. 3. A-B)

Harley et al. 25140 (CTES, K, SPF); Mello-Silva et Cordeiro CFCR 10010 (CTES, SPF); Pirani et al. CFCR 8539 (CTES, SPF); Pirani et al. CFCR 11399 (CTES, SPF).

Minas Gerais y Rio de Janeiro, en "cerrados" y "campos rupestres". En Grão-Mogol, en campos rupestres con afloramientos rocosos. Florece en setiembre, fructifica en noviembre.

\section{Paullinia L.}

Trepadoras monoicas. Tallos con cámbium único o cámbiumes supernumerarios. Hojas imparipinnadas, 1-3-compuestas, con estípulas. Tirsos o tirsos dobles, axilares o terminales. Flores zigomorfas, blanquecinas. Cáliz 5-mero. Corola 4-mera, pétalos con escama basal petaloidea. Glándulas nectaríferas 4. Androceo excéntrico, 8 estambres. Gineceo excéntrico, 3-carpelar, 1 óvulo por carpelo. Cápsulas rojas, septífragas. Semillas ariladas.

5.1. Paullinia carpopodea A.St.-Hil., A.Juss. \& Cambess. in A.St.-Hil., Fl. Bras. merid. 1: 376, tab. 78 B. 1828.
Trepadoras glabriúsculas o pubescentes. Tallo terete, lenticelas notables; cámbium único. Lámina 2-4-yugada, 
generalmente el par basal con 3 foliólulos, raquis y pecíolo ápteros o alados, folíolos con peciólulo o subsésiles, subcoriáceos, elípticos, obovado-angostos u oblongos, enteros, revolutos, ápice en acumen obtuso mucronado o retuso, haz glabro, envés glabro a pubescente, 2,4-13 cm long., 0,85-4,7 $\mathrm{cm}$ lat. Cincinos pedunculados o subsésiles. Flores 4-6 mm long. Sépalos con pelos adpresos, 2 de los sépalos internos soldados en su mayor parte. Pétalos eglandulosos. Frutos subglobosos, estipitados, 1-1,8 cm long., 1,2-2,1 cm lat., in- cluido el estípite de 0,5-1,5 cm long., epicarpo glabro, endocarpo glabriúsculo. (Fig. 2. A-B)

Zappi et al. CFCR 13018 (SPF).

Bahia, Espirito Santo, Distrito Federal, Paraná, Rio de Janeiro, Santa Catarina y Minas Gerais. En Grão-Mogol, en "mata montana". Florece en marzo-mayo; fructifica en octubre.

\section{Serjania Mill.}

Trepadoras monoicas, raro sufrútices erectos o rastreros. Tallos con cámbium único o cámbiumes supernumerarios. Hojas imparipinnadas, 1-3-compuestas, con estípulas. Tirsos o tirsos dobles, axilares o terminales. Flores zigomorfas, generalmente blanquecinas. Cáliz 5-mero. Corola 4-mera, pétalos con escama basal petaloidea. Glándulas nectaríferas 4. Androceo excéntrico, 8 estambres. Gineceo excéntrico, 3-carpelar, 1 óvulo por carpelo. Frutos esquizocárpicos, mericarpos samaroideos, lóculos apicales, alas descendentes.

\subsection{Serjania acutidentata Radlk., Consp. sect. sp. Serjan.: 11. 1874.}

Trepadoras glabriúsculas. Tallo hexangular, 3 ángulos obtusos que alternan con 3 ángulos prominentes; cámbiumes supernumerarios 3(4). Lámina 2-yugada, par basal con 3 foliólulos; folíolos sésiles o subsésiles, subcoriáceos, oblongos u obovados, con 2-4(5) dientes obtusos subapicales, raro algunos folíolos enteros, subrevolutos, ápice agudo- u obtuso-mucronado, raro emarginados, 1-8,3 cm long., 1-3,7 cm lat. Flores 3,5-4 mm long. Sépalos externos pubérulos, los internos con pelos crespos. Pétalos eglandulosos. Frutos cartáceos, de contorno ovado-cordados, 1,8-2,5 cm long., 1,4-2,4 cm lat., lóculos hinchados con cresta dorsal angosta; epicarpo pubescente en porción seminífera; endocarpo pubérulo. (Fig. 1. N-O)

Hatschbach et al. 67967 (CTES, MBM); Pirani et al. CFCR 8316 (CTES, SPF); Silva et al. CFCR 13398 (CTES, SPF); Simão-Bianchini et al. CFCR 13012 (CTES, SPF).

Bahia y Minas Gerais. En Grão- Mogol, en "mata montana", transición "cerrado-mata". Florece de mayo hasta setiembre; fructifica desde setiembre hasta marzo.

6.2. Serjania lethalis A.St.-Hil., Bull. Sci. Soc. Philom. Paris 77. 1824.

Trepadoras glabriúsculas. Tallo subterete, con frecuencia pruinoso; cámbiumes periféricos 3-4(5). Lámina 2-yugada, par basal con 3 foliólulos; raquis primario y secundario marginados o bicanaliculados; folíolos oblongos, elípticos u obovado-angostos, enteros o dentado-serrados, haz glabro o laxamente glandular, envés con glándulas microscópicas, 3-12 cm long., 1,5-5,5 cm lat. Inflorescencias largas, pubescentes, cincinos pedunculados. Flores 3-6 mm long.
Sépalos pubescentes. Pétalos glandulosos. Frutos cartáceos, ovado-cordados, 1,2-3,5 cm long., 2-2,7 cm lat., lóculos globosos, epicarpo velloso o pubescente, alas pubérulas o glabras; endocarpo pubérulo o glabro. (Fig. 1. K-M)

Campos et al. CFCR 13505 (CTES, SPF); Carvalho et al. 6578 (CEPEC, CTES); Mello-Silva et al. CFCR 10133 (CTES, SPF); Silva et al. CFCR 13526 (CTES, SPF).

Perú, Bolivia y Brasil (desde Ceará hasta Santa Catarina). En Grão-Mogol, en orilla de "cerradão" y de ríos. Florece desde agosto hasta noviembre y fructifica desde octubre hasta diciembre.

6.3. Serjania paradoxa Radlk., Consp. sect. sp. Serjan.: 6. 1874.

Trepadoras glabriúsculas o pubescentes. Tallo con 5 costillas; 5 cámbiumes radiales, leño dividido en 5 masas xilemáticas. Lámina 2-yugada, par basal con 3 foliólulos; folíolos sésiles o peciolulados, cartáceos, oblongos, elípticos u ovados, enteros o dentado-serrados, 3,7-8,8 cm long., 1,2-3,4 cm lat. Cincinos basales subverticilados y largamente pedunculados. Flores 4-6 $\mathrm{mm}$ long. Sépalos externos glabros o pubescentes, los internos velutinos. Pétalos escasamente glandulosos. Frutos cartáceos, de contorno ovado-cordado o subrectangular, 2-3,6 cm long., 2-3,5 cm lat., lóculos complanados con cresta dorsal notable; epicarpo y endocarpo glabros o pubescentes. (Fig. 1. F-H)

Cordeiro et al. CFCR 806, CFCR 843 (CTES, SPF); Esteves et al. CFCR 13390 (CTES, SPF); Freire-Fierros et al. CFCR 12361 (CTES, SPF); Harley et al. CFCR 6486, CFCR 6492 (CTES, SPF); Pirani et al. CFCR 13013 (CTES, SPF); Sano et al. CFCR 12552 (CTES, SPF).

Bahia, São Paulo y Minas Gerais. En Grão-Mogol, en "cerrado", "carrascal", borde de mata montana y campos rupestres. Suelo arenoso fino con rocas. Florece de setiembre hasta junio; fructifica desde noviembre hasta agosto. 


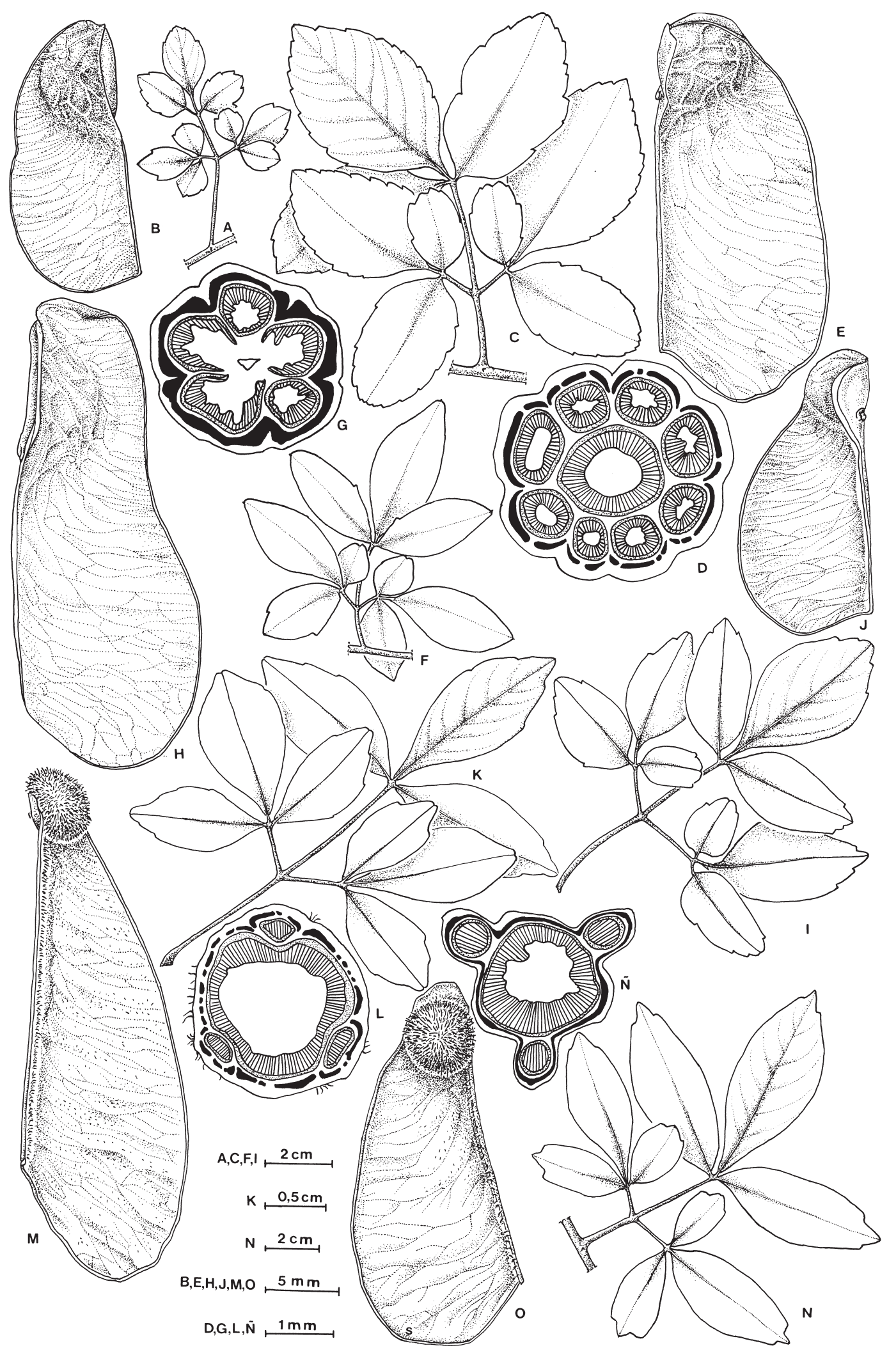

Fig. 1. SAPINDACEAE. Serjania. A-B. S. suborbicularis: A. Hoja; B. Mericarpo. C-E. S. purpurascens: C. Hoja; D. Corte transversal de tallo; E. Mericarpo. F-H. S. paradoxa: F. Hoja; G. Corte transversal de tallo; H. Mericarpo. I-J. S. reticulata: I. Hoja; J. Mericarpo. K-M. S. lethalis: K. Hoja; L. Corte transversal de tallo; M. Mericarpo. N-O. S. acutidentata: N. Hoja; Ñ. Corte transversal de tallo; O. Mericarpo. 
6.4. Serjania purpurascens Radlk., Consp. sect. sp. Serjan.: 16. 1874.

Trepadoras, con tallos jóvenes, ejes de la hoja e inflorescencia ferrugíneo-pubescentes. Tallo con 8-10 costillas; 8-10 cámbiumes periféricos. Lámina 2-yugada, par basal con 3 foliólulos; folíolos cartáceos, ovados u oblongos, dentadoserrados, 3-10,5 cm long., 1,8-5,6 cm lat., glabriúsculos. Cincinos brevemente pedunculados. Flores 5-6 mm long. Sépalos externos pubescentes, los internos velutinos. Pétalos glandulosos. Frutos cartáceos, de contorno ovado-ancho, 2,3-2,8 mm long., 1,8-2,4 mm lat., lóculos hinchados; epicarpo y endocarpo glabros. (Fig. 1. C-E)

Carvalho et al. 6580 (CEPEC, CTES); Freire-Fierros et al. CFCR 12718 (SPF); Hatschbach et al. 42849, 54217, 54219 (CTES); Pirani et al. CFCR 883, CFCR 13005, CFCR 13007 (CTES, SPF).

Rio de Janeiro y Minas Gerais. En Grão-Mogol, en borde de "mata montana", entre los 950-1050 m s.m. Florece de abril-junio y fructifica en mayo-julio.

6.5. Serjania reticulata A.St.-Hil., A.Juss. \& Cambess. in A.St.-Hil., Fl. Bras. merid. 1: 359. 1828.

Trepadoras glabriúsculas o pubescentes. Tallo geniculado, con 5 ó 6 costillas poco marcadas; cámbium único. Lámina 2-yugada, par basal con 3 foliólulos; folíolos peciolulados, cartáceos, discolores, oblongos u ovados, dentado-serrados, raro algunos folíolos enteros, ápice obtuso-, agudo-, retuso o en acumen obtuso mucronulado o glandular, envés glabro o pubescente, $3-8,5 \mathrm{~cm}$ long., 1,5$5 \mathrm{~cm}$ lat. Cincinos pedunculados. Flores 4-5,5 mm long. Sépalos externos glabros o pubérulos, los internos velutinos. Pétalos glandulosos. Frutos cartáceos, de contorno ovado-cordado, con constricción debajo del lóculo, 1,5-
3,3 cm long., 1,2-2,8 cm lat., porción seminífera hinchada con o sin cresta dorsal, epicarpo glabro raro pubérulo; endocarpo incano lanoso. (Fig. 1. I-J)

Hatschbach et al. 54286 (CTES); Zappi et al. CFCR 13014, CFCR 13209 (CTES, SPF)

Brasil (Goiás, Mato Grosso, Paraná, Rio de Janeiro, Santa Catarina, São Paulo y Minas Gerais) y Bolivia. En GrãoMogol, en "mata montana", en "cerrado" y en "campo rupestre". Florece en marzo-abril; fructifica en junio-agosto.

6.6. Serjania suborbicularis Radlk. in Mart., Fl. bras. 13(3): 329. 1892.

Trepadoras glabriúsculas. Tallo con 6 costillas; cámbium único. Lámina 2-yugada, par basal con 3 foliólulos; folíolos peciolulados, cartáceos, obovados u ovado-angostos, dentado-serrados, 0,9-2,1 cm long., 0,5-1,2 cm lat. Cincinos subverticilados, brevemente pedunculados. Flores 4-4,5 mm long. Sépalos glabros. Pétalos densamente glandulosos. Frutos cartáceos, de contorno suborbicular, sin constricción debajo del lóculo, 1,45-1,6 cm long., 1,4-1,8 cm lat., lóculos hinchados; glabros. (Fig. 1. A-B)

Carvalho et al. 6518 (CEPEC, CTES); Furlan et al. CFCR 735 (CTES, SPF); Harley et al. CFCR 6483 (CTES, SPF); Irwin et al. 23378 (K); Mamede et al. CFCR 3396, CFCR 3486 (CTES, SPF); Menezes et al. CFCR 9635 (CTES, SPF); Pirani et al. CFCR 8949 (CTES, SPF); Silva et al. CFCR 12493 (CTES, SPF); Simão-Bianchini et al. CFCR 12955 (CTES, SPF); Zappi et al. CFCR 11960 (CTES, SPF).

Endémica en Minas Gerais, Sierra de Biribiri y GrãoMogol. Trepadora entre rocas, a veces a la orilla de cursos de agua. Florece desde diciembre hasta mayo; con frutos en abril-julio.

\section{Toulicia Aubl.}

Árboles, arbustos o subarbustos monoicos. Hojas paripinnadas, menos frecuente imparipinnadas, compuestas, estípulas ausentes. Inflorescencias muy desarrolladas, tirsos dobles o pleiotirsos, terminales o subterminales. Flores zigomorfas o actinomorfas, de color crema. Cáliz 5-mero. Corola 4-5-mera, pétalos con escama basal. Disco o hemidisco nectarífero. Androceo con 8 estambres. Gineceo 3-carpelar, 1 óvulo por carpelo. Frutos esquizocárpicos, mericarpos samaroideos, lóculos apicales, alas descendentes.

7.1. Toulicia tomentosa Radlk., Sitzungsber. Math.-Phys. Cl. Königl. Bayer. Akad. Wiss. München 8: 373. 1878.

Arbustos o subarbustos erectos, 1-4 m alt., rizomatosos. Indumento denso, amarillento a ferrugíneo, en tallo, ejes de la hoja e inflorescencia. Lámina con 4-10 folíolos, folíolos sésiles o subsésiles, cartáceos o subcoriáceos, oblongos u ovado-angostos, enteros, haz brillante, envés opaco, pubescente, 3,5-13,5 cm long., 1,8-5,4 cm lat. Inflorescencias parciales glomérulos sésiles o subsésiles. Flores actinomorfas, 4-6 mm long. Sépalos 5, pétalos 5, seríceos en la cara aba- xial. Disco glabro. Filamentos estaminales incano-vellosos. Gineceo velloso. Frutos cartáceos, de contorno oblongo- u ovado-ancho, apiculados, 2,8-3,7 cm long., 2,5-2,9 cm lat., pubescentes. (Fig. 2. E-G)

Mello-Silva et al. CFCR 9850 (CTES, SPF); Pirani et al. CFCR 8352 (CTES, SPF).

Brasil y Paraguay nordoriental, en cerrados. En GrãoMogol, en suelo arenoso con rocas. Florece desde febrero hasta julio, con frutos desde junio hasta setiembre. 


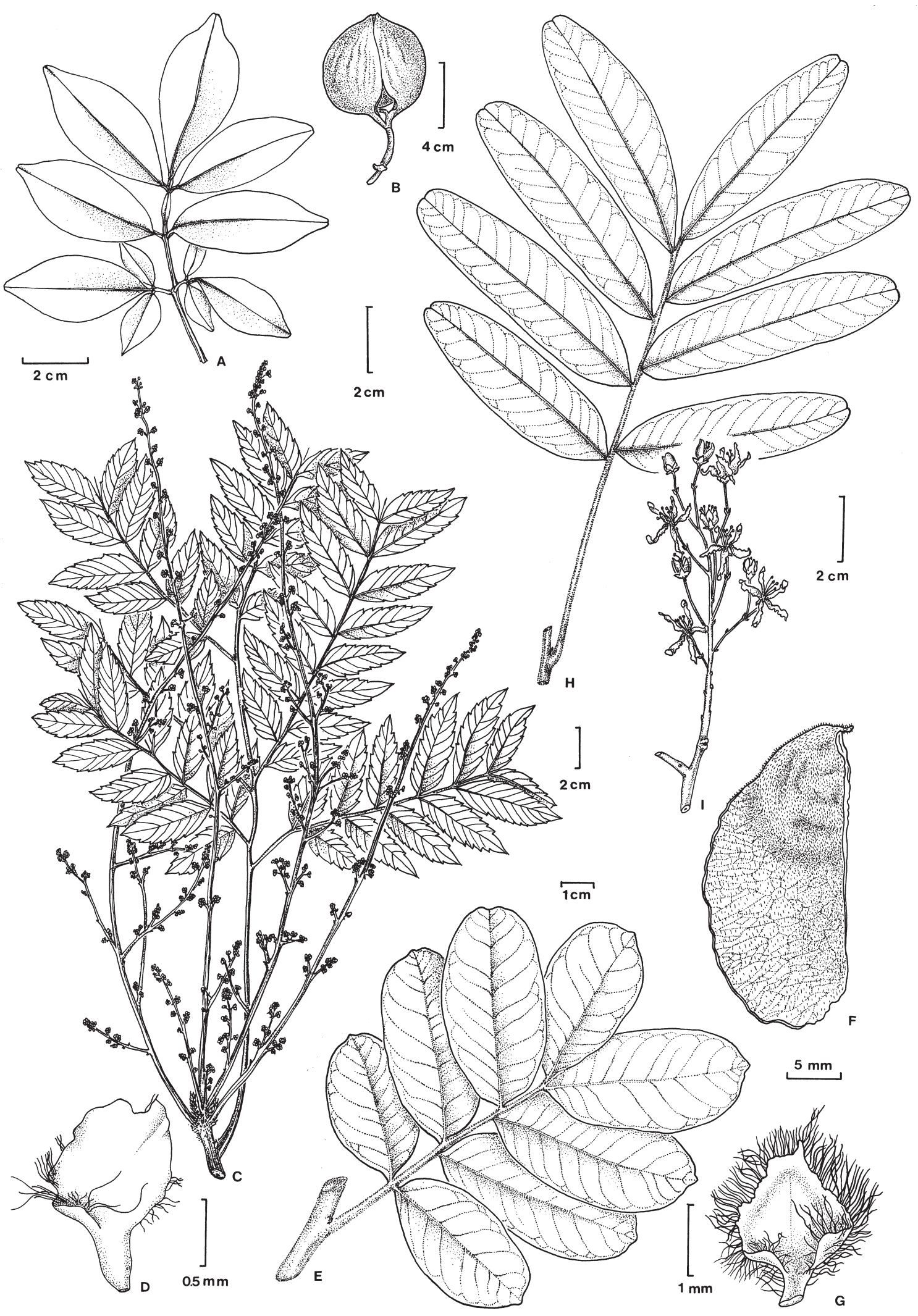

Fig. 2. SAPINDACEAE. A-B. Paullinia carpopodea: A. Hoja; B. Fruto. C-D. Dilodendron bipinnatum: C. Rama florífera; D. Pétalo, cara interna. E-G. Toulicia tomentosa: E. Hoja joven; F. Mericarpo; G. Pétalo, cara interna. H-I. Magonia pubescens: H. Hoja; I. Rama florífera. 

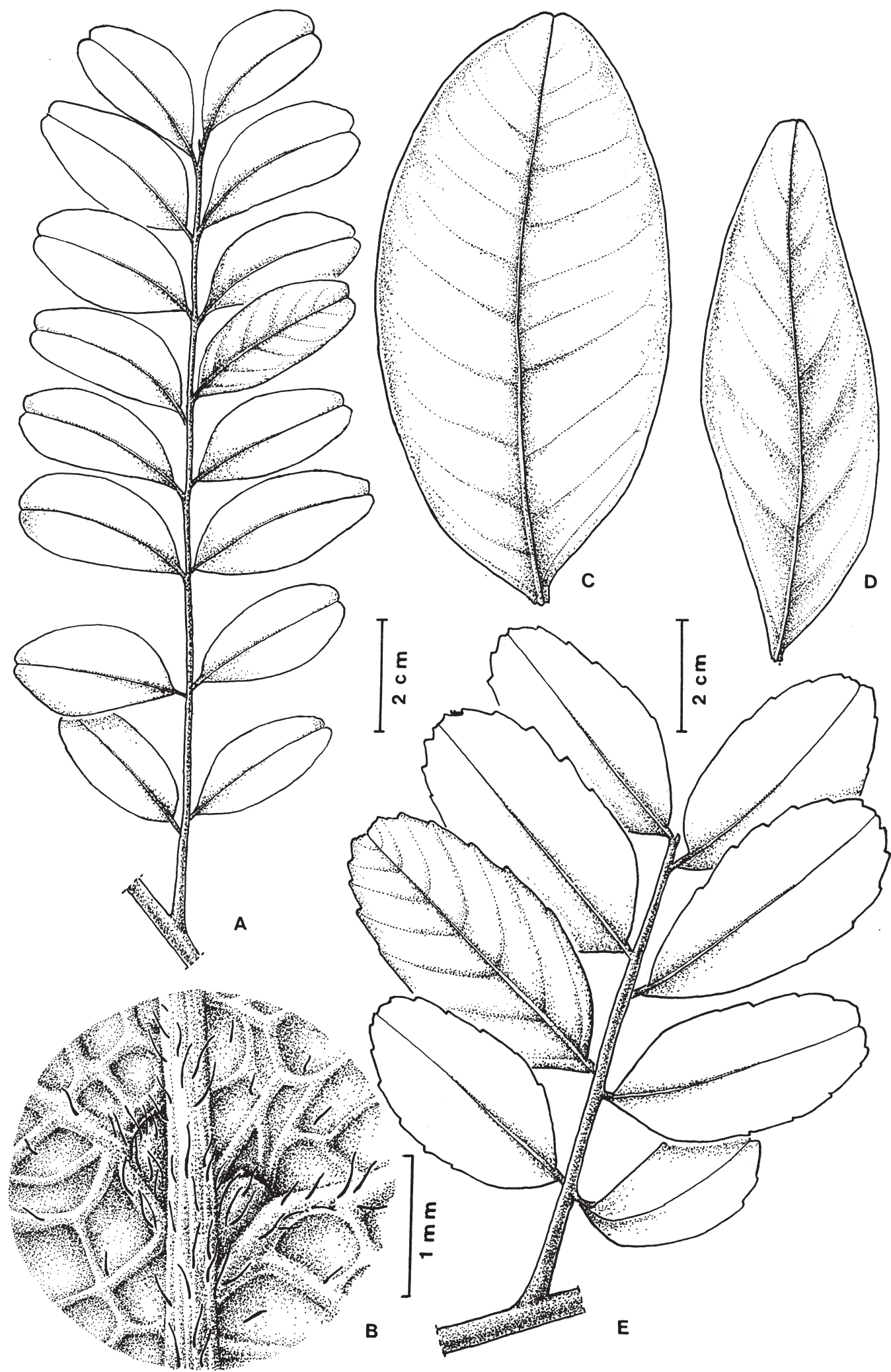

Fig. 3. SAPINDACEAE. A-B. Matayba marginata: A. Hoja; B. Detalle del envés mostrando sendos domacios. C. M. juglandifolia: envés del folíolo mostrando venas laterales de primer orden, rectas, ascendentes. D. M. guianensis: envés del folíolo mostrando venas laterales de primer orden curvas, ascendentes. E. Cupania paniculata: hoja. 